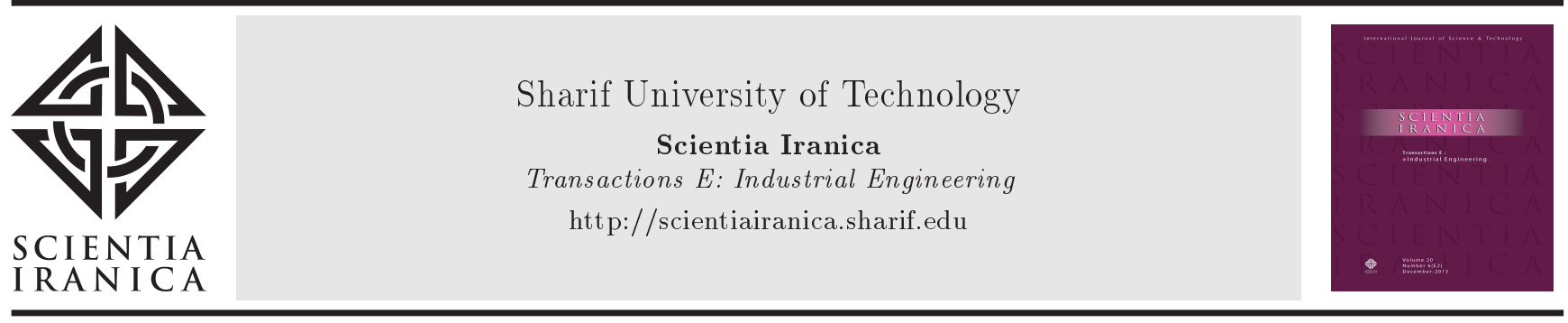

Research Note

\title{
Efficiency measurement for hierarchical network systems using network DEA and intuitionistic fuzzy ANP
}

\author{
E. Shariatmadari Serkani ${ }^{a}$, F. Hosseinzadeh $\operatorname{Lotfi}^{b}$, E. Najafi, ${ }^{a, *}$ and \\ M. Ahadzadeh Namin ${ }^{c}$ \\ a. Department of Industrial Engineering, Science and Research Branch, Islamic Azad University, Tehran, Iran. \\ b. Department of Mathematics, Science and Research Branch, Islamic Azad University, Tehran, Iran. \\ c. Department of Mathematics, Shahr-e-Qods Branch, Islamic Azad University, Tehran, Iran.
}

Received 11 October 2019; received in revised form 21 July 2020; accepted 14 September 2020

\author{
KEYWORDS \\ Efficiency; \\ Ranking; \\ Network data \\ envelopment analysis; \\ Hierarchy structure; \\ Intuitionistic fuzzy; \\ Analytic network \\ process.
}

\begin{abstract}
Regarding the high importance of university in the growth and development of a country, the efficiency of educational and research groups in universities is a vital consideration. The black box Data Envelopment Analysis (DEA) model is mathematical programming for measuring the relative efficiency of a set of Decision-Making Units (DMUs) without considering the operations of the component processes that may have misleading results. To overcome this problem, network models are recommended. This paper intends to propose a hybrid Intuitionistic Fuzzy Analytic Network Process (IFANP) and Network DEA (NDEA) technique to evaluate the efficiency of the Faculty of Basic Sciences of Islamic Azad University. IFANP was used to evaluate the overall weights among all the criteria and sub-criteria and the weights were in turn used in the NDEA model to measure the relative efficiency. A hypothetical example showed that the efficiency of all DMUs was equal to 1 by using the DEA and there was no ranking among the DMUs. The results of the IFANP-NDEA could be more meaningful with full ranking of the DMUs considering the component process operations. Finally, the model could prioritize the efficient DMUs and determine the efficiencies of the DMUs' functions. This model enables managers to identify the areas of weakness in the subject under their study.
\end{abstract}

(C) 2022 Sharif University of Technology. All rights reserved.

\section{Introduction}

Efficiency measurement is an important task in management, which not only indicates the past achieve-

\footnotetext{
*. Corresponding author.

E-mail addresses: e.shariatmadari@srbiau.ac.ir (E.

Shariatmadari Serkani); farhad@hosseinzadeh.ir (F. Hosseinzadeh Lotfi); najafi1515@yahoo.com (E. Najafi); mahnazahadzadehnamin@gmail.com (M. Ahadzadeh Namin)
}

doi: $10.24200 /$ sci.2020.54619.3836 ments of a unit, but also represents the orientations of development in the future. On the other hand, having an efficient evaluation system is necessary for universities, like every other organization, to be aware of the desirability of their activities, especially in complex and dynamic environments. Considering the role of education and research in the production of science, which are today the responsibility of universities and higher education institutions, normally there is an essential need for designing systems of efficiency evaluation for such institutions in order to ensure that this task is realized and/or facilitated. In this regard, 
identifying the pros and cons the subsystems of these institutions should be examined using specific criteria and scientific principles.

The Data Envelopment Analysis (DEA) model is considered as an effective method to measure the relative efficiency of Decision-Making Units (DMUs), which uses multiple inputs to generate multiple outputs. System evaluation through the conventional DEA models considers DMUs as black boxes regardless of their internal structure [1]. As a result, a system may be introduced as an efficient system while all its process components are not efficient. Significantly, there are cases in which all process components of a DMU work worse than other DMUs and, at the same time, they have a better system performance.

For the first time, Färe and Grosskopf [2] presented an article that studied the importance of Network DEA (NDEA). There are different NDEA models with regard to various structures of the systems. A hierarchical system can be divided into two groups of multicomponent or multi-function depending on whether each section has the same efficiency. In the multicomponent system, sections have the same function at all levels. In this type of system, there is no need to have the same number of sections in each level for different DMUs. Multicomponent hierarchy system is a network system with different levels of sections, while all sections use similar inputs to generate similar outputs. A multifunction system consists of several sections with different functions, where various inputs are used to generate different outputs.

Nowadays, we encounter several types of MultiCriteria Decision-Making (MCDM) analysis in daily life. The decision-making process faces many quantitative and qualitative criteria. The Analytic Hierarchy Process (AHP) has been introduced by Saaty and is considered as one of the most comprehensive systems designed for MCDM. Compatibility or incompatibility of a decision can also be evaluated by this method. This method can be employed when decision-making faces multiple alternatives and several decision-making indicators. In 1996, Saaty [3] provided a method for MCDM, called the Analytic Network Process (ANP).

The ANP method, which has been developed from the AHP, can consider correlations and feedback between effective elements in decision-making. In ANP, the decision-makers' opinions are expressed in the form of certain numbers. However, this is not always possible due to ambiguity and uncertainty in evaluation considering the fact that many of the criteria are inherently qualitative and subjective; hence, it becomes impossible for a decision maker to assign a certain number to such criteria.

Some decision-making problems usually include imprecise, uncertain data that make the decision making process more complex. To reflect the attribute- related information, most decision-makers tend to give linguistic variables or fuzzy variables instead of crisp values.

Fuzzy set theory was proposed by Zadeh [4,5] to reflect the uncertainties in human judgment. One of the applications of the fuzzy theory is fuzzy MCDM. For this purpose, in most of the solution methods of AHP, fuzzy numbers are used to conduct pairwise comparisons, where membership functions are employed as the basis for determining the weights of the criteria and sub-criteria. Huang [6] proposed a novel Fuzzy ANP (FANP) model by solving a mathematical programming problem. Li et al. [7] used a generalized fuzzy number, which represented a different fuzzy number when the parameter changed.

In the decision-making process, the weight indicators or experts play an important role, as they have a direct effect on the accuracy of decision-making and ranking of the results for alternatives. The evaluation criteria usually include diverse opinions, so it is impossible to assume that each evaluation criterion is equally important [8]. The subjective methods determine the weights of indicators in terms of the subjective preference of decision-makers. The Delphi method [9] and AHP [10] are samples of subjective methods.

In objective methods such as DEA [11] and entropy, the weights of indicators are achieved using objective decision matrix information or solving mathematical models. Subjective and objective methods have both advantages and disadvantages. For example, subjective methods can use the opinions of experts, yet objective methods are not dependent on human factors and ignore the opinion and experience of experts. For careful and scientific decisions, decision-makers need to provide qualitative or quantitative evaluations to determine the relative importance of evaluation criteria.

In this regard, some integration methods have been proposed in many references [12-16]. For instance, Li et al. [17] proposed a dynamic fuzzy MCDM method, which considered the integrated weight of decision makers with subjective and objective preferences.

The classical DEA method considers organizations as a black box, limits their calculations to primary inputs and outputs, and neglects internal processes. Cook et al. [18] in a study introduced a separate model to determine the efficiency of existing units at each level and then, integrated the scores of two levels using three-step approaches. Sexton and Lewis [19] presented a two-stage DEA method to measure the efficiency of units that were produced in two stages. Mikhailov [20] presented a new approach to extracting priorities from a pairwise comparison matrix based on the fuzzy alpha-cut analysis in a series of interval comparisons. Cook and Green [21] in another study 
introduced a hierarchical model that simultaneously calculated the efficiency of existing units at each level in order to maximize efficiency at a higher level. Kao [22] conducted a study in which each network system was converted into a serial system using virtual processes and each step comprised in a series of systems with parallel structure. Chen et al. [23] developed two-stage models of the DEA analysis by changing the technology and ranked the DMUs. Castelli et al. [24] classified the main DEA models to evaluate the efficiency of DMUs wherein the internal structures were considered as black boxes, but domestic processes were incorporated. Kao and Hwang [25] used two serial and parallel structures of several models to evaluate the network DMUs that were defined based on the efficiency of the units. They measured the efficiency of the two-step process for 24 insurance companies in Taiwan. Cook et al. [26] presented a multi-stage NDEA with a parallel process. Chen and Yan [27] proposed a DEA model to evaluate the supply chain performance in centralized, decentralized, and hybrid modes. Despotis et al. [28] examined the NDEA by presenting a multi-objective linear programming model into the assessment of the academic research activity. Kashim et al. [29] presented an NDEA model with a parallel structure for effectiveness measurement of universities. The model included internal operations of educational and research functions in calculating the effectiveness of an academic system. Guo et al. [30] studied two-stage NDEA models with shared resources. Shafaghizadeh et al. [31] proposed combining the two approaches of resilience and chance-constrained NDEA to measure the performance of decision-making and analyze the resilience of the supply chain using DEA in conditions of uncertainty.

Mikhailov and Singh [32] presented a fuzzy extension of ANP that used unknown human preferences as input data to the decision-making process and they implemented a new Fuzzy Preference Programming (FPP) method. Mikhailov and Tsvetinov [33] introduced a new approach to coping with the uncertainty and ambiguity of the service evaluation process. Liu and Wang [34] presented new methods for solving MCDM problems in an intuitionistic fuzzy environment. Rouyendegh and Erol [35] introduced a DEAFANP model to fully rank the departments of Amir Kabir University. Lin [36] developed decision support tools by using the Fuzzy DEA and ANP in order to select the personnel of an electrical and machinery company in Taiwan. Chen et al. [37] used the ANPDEA model for optimization of decision-making on railway emergency plans. Özdemir [38] used a twostage approach by combining ANP and DEA to evaluate the financial performance of banks. Zhang and Liu [39] proposed integrating ANP and game crossefficiency DEA model to analyze the vulnerability of interdependent infrastructures. Ehsanifar [40] performed a full ranking of DMUs using the DEA-ANP model. In this study, a fuzzy priority method was proposed, the comparison ratios were employed instead of exact numerical values, and the initial fuzzy preference was converted into a nonlinear programming. Cui and Fang [41] used a hybrid DEA-ANP method that allowed assessing the relative complexity scores of engineering projects. Kumar et al. [42] used the Fuzzy AHP (FAHP) and DEA hybrid approach in order to achieve relative efficiency in identifying inefficient service providers. Tavakoli et al. [43] introduced the ANP-DEA method for ranking organizational units as well as prioritizing an organization's human capital management. Abdullah and Najib [44] adopted a new IFAHP to establish a preference in the sustainable energy planning decision-making problem. $\mathrm{Hu}$ et al. [45] proposed the DEA/AHP hybrid approach by conducting a pairwise comparison of AHP with fuzzy DEA and used AHP to completely rank the units. Shariati et al. [46] proposed a new model based on the Intuitionistic Fuzzy Sets (IFSs) and ANP technique to evaluate the critical factors of the application of nanotechnology to the construction industry. Salehian et al. [47] proposed a novel hybrid algorithm based on FAHP and DEA for measuring the efficiency of product transportation in road fleets of the Iranian provinces. Mazumder et al. [48] developed a decision support framework by integrating the ANP and DEA approach in a manufacturing environment. Li et al. [49] investigated an intuitionistic fuzzy multiple-attribute decision-making method based on weighted induced distance and applied it to an investment selection problem.

Kao [50] proposed the development of an NDEA model for hierarchical structure systems. Furthermore, Kao [51] studied the NDEA and multi-stage serial processes and provided a full classification of studies on NDEA with respect to the type of network structure and the model used. The series and the parallel production processes have been widely studied in literature. Lee and Worthington [52] presented an NDEA model for the research operations of the Australian universities with regard to both quality and quantity. Koronakos et al. [53] evaluated the research performance of computer science in the UK through the NDEA approach. Koronakos [54] provided descriptions of the notions underlying the NDEA methods and discussed their advantages over the classical DEA methodologies. Koronakos also provided a full classification of a large volume of literature on DEA in a unified manner. Chen et al. [55] identified several pitfalls in the modeling of NDEA, originating from a simple two-stage network structure wherein only intermediate measures existed between two stages, with the first stage having only input and the second stage 
only output. They discussed the difference between two types of NDEA models, namely multiplier and envelopment, and pointed out the functions of each.

This study is aimed to investigate the efficiency of the Faculty of Basic Sciences of the Islamic Azad University, in two areas of education and research, using the Intuitionistic Fuzzy ANP (IFANP) and NDEA methodologies.

This paper is organized as follows: a preliminary introduction to the NDEA and IFANP is presented in Section 2. This section provides basic definitions for intuitionistic fuzzy and triangular fuzzy numbers. In addition, an insight into the basics of the IFSs is provided. Section 3 explains the methodology and a numerical example is discussed in Section 4. Finally, Section 5 concludes the research.

\section{Basic concepts}

\subsection{Intuitionistic fuzzy set}

Atanassov [56,57] introduced the logics of the IFSs in 1986. The author presented the IFS as a generalization of the fuzzy sets, known by the membership function, the non-membership function, and the hesitancy function. Intuitionistic fuzzy can be used when there are doubts. Indeed, IFSs consider degrees for membership and non-membership functions, offering a suitable method to tackle the uncertainty that may govern an issue in hand. The degree of uncertainty reflects the fact that decision-makers will not be able to select a certain membership degree in all cases. However, the novelty of the present paper lies in putting forward a new model using the intuitionistic fuzzy data.

Definition 1: If $X$ is a fixed infinite set, the IFS A in the reference set $x$ is defined as:

$$
A:=\left\{<x, \mu_{A}(x), v_{A}(x)>x \in X\right\},
$$

where, $\mu_{A}(x): x \rightarrow[0,1]$ and $v_{A}(x): x \rightarrow[0,1]$ determine the degrees of membership and non-membership of the element $x \in X$, respectively. For each $x \in X$, for $\mu_{A}$ and $v_{A}$, we have:

$$
0 \leq \mu_{A}(x)+v_{A}(x) \leq 1
$$

Definition 2: $\pi_{\bar{a}}(x)$ is the hesitancy intuitionistic fuzzy index of the element $x$ in $\bar{a}$, if $\pi_{\bar{a}}(x)=1-\mu_{\bar{a}}(x)-$ $v_{\bar{a}}(x)$.

Definition 3: Triangular Intuitionistic Fuzzy Number (TIFN) $\tilde{a}=\left\langle(\underline{a}, a, \bar{a}) ; \omega_{\tilde{a}}, u_{\tilde{a}}\right\rangle$ is an IFS that is defined on the set of real numbers of $R$ with the membership function $\mu_{\tilde{a}}(x)$ and non-membership function $v_{\bar{a}}(x)$ as follows:

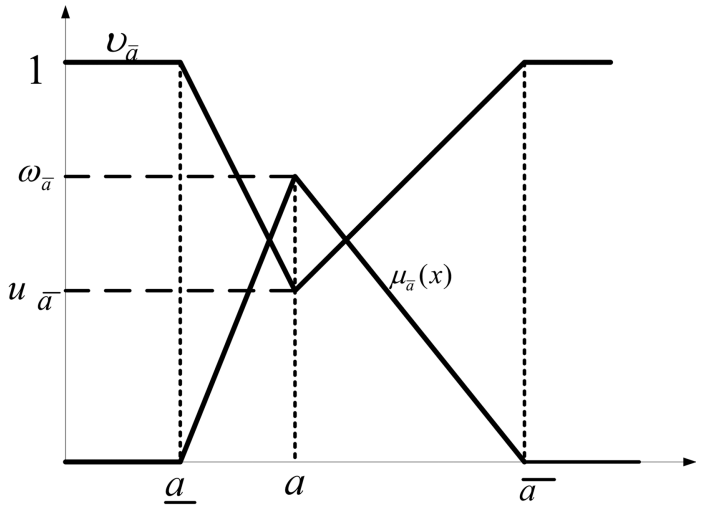

Figure 1. Triangular Intuitionistic Fuzzy Number (TIFN), $\operatorname{TIFN}_{\tilde{a}=\left\langle(\underline{a}, a, \bar{a}) ; \omega_{\bar{a}}, u_{\bar{a}}\right\rangle}$.

$$
\begin{aligned}
& \mu_{\tilde{a}}(x)= \begin{cases}\frac{(x-\underline{a}) \omega_{\bar{a}}}{(a-\underline{a})} & \text { if } \quad \underline{a} \leq x<a, \\
\omega_{\tilde{a}} & \text { if } \quad x=a, \\
\frac{(\bar{a}-x) \omega_{\bar{a}}}{(\bar{a}-a)} & \text { if } \quad a<x \leq \bar{a}, \\
0 & \text { if } \quad x<\underline{a} \text { or } x>\bar{a}\end{cases} \\
& v_{\bar{a}}(x)= \begin{cases}\frac{a-x+(x-\underline{a}) u_{\bar{a}}}{(a-\underline{a})} & \text { if } \underline{a} \leq x<a, \\
u_{\tilde{a}} & \text { if } x=a, \\
\frac{\left[x-a+(\bar{a}-x) u_{\bar{a}}\right]}{(\bar{a}-a)} & \text { if } a<x \leq \bar{a}, \\
1 & \text { if } x<\underline{a} \text { or } x>\bar{a}\end{cases}
\end{aligned}
$$

As shown in Figure 1, the variables $u_{\tilde{a}}$ and $\omega_{\tilde{a}}$ representing the maximum degree of membership and the minimum degree of non-membership, respectively, meet the condition $0 \leq u_{\tilde{a}}+\omega_{\tilde{a}} \leq 1$, and $0 \leq u_{\tilde{a}} \leq 1$, and $0 \leq w_{\tilde{a}} \leq 1$.

\subsection{Intuitionistic fuzzy $A N P$}

The ANP process has been widely used for decisionmaking in dealing with real problems. However, despite its simplicity and efficiency, the process has been criticized for coming short in incorporating the inaccuracy and uncertainty of the perceptions of decisionmakers. In the normal ANP, the decisions of the decision-makers are expressed in the form of definite numbers, while this may not be appropriate due to the ambiguity and uncertainty of assessment. Of note, many criteria are intrinsically qualitative and subjective, hence assigning definite numbers to them in the evaluations is impossible for the decisionmaker. Therefore, decision-makers prefer to use fuzzy numbers for this purpose. Factors such as inadequate information and knowledge, complexity and intrinsic uncertainty of decision-making environments, and the lack of appropriate criteria make decisionmakers more vulnerable in prioritization. Making comparisons based on fuzzy numbers is easier for the decision-makers, because it is more consistent with the uncertain nature of human judgments. For this reason, many researchers have tried to develop the 
ANP process to the fuzzy space using the fundamental concepts of fuzzy sets theory and, especially, fuzzy numbers. In regard to this, triangular and trapezium fuzzy numbers have more frequently been employed, because the membership functions of such continuous numbers are uniformly ascending or descending. As a result, they are more easily understandable and math operations such as summation and multiplication on them are done in a simpler way. The purpose of the IFANP method is to maximize the membership functions as well as to minimize the non-membership functions, for which multi-objective modeling is used. The optimal solutions to this problem are those that maximize the degree of membership and minimize the degree of non-membership. According to this definition, the optimal solution will be obtained from the interfaces of the constraints and the objective function.

Mikhailov's fuzzy preferences linear programming can be used to solve such problems as follows.

Consider a preference problem with $n$ elements wherein paired comparison judgments are shown with normal fuzzy sets or fuzzy numbers. Mikhailov and Singh [32] proposed FPP to derive priority vectors from a set of interval comparisons.

Assume that the decision-maker provides a set $F=\left\{\tilde{a}_{i j}\right\}$ with the fuzzy paired comparisons of:

$$
\begin{aligned}
& i=1, \cdots, n-1 ; \quad j=2, \cdots, n ; \quad i<j ; \\
& m=n(n-1),
\end{aligned}
$$

in the form of triangular fuzzy numbers $\tilde{a}_{i j}=$ $\left(l_{i j}, m_{i j}, u_{i j}\right), \delta_{i j}, \varepsilon_{i j}$. In other methods, $n(n-1)$ comparisons are needed to calculate the weight vector for $n$ factors, but in the Mikhailov method, the weight of the factors can be calculated with any number of comparisons $m=n(n-1)$.

Suppose that $\tilde{a}_{i j}=\left(l_{i j}, m_{i j}, u_{i j}\right), \delta_{i j}, \varepsilon_{i j}$, then the priority vector of $w=\left(w_{1}, \cdots, w_{n}\right)^{T}$ can be obtained based on the matrix of mental judgments and membership and non-membership functions, whose ratio is almost precise in the initial judgments, $\tilde{a}_{i j}=$ $\left(l_{i j}, m_{i j}, u_{i j}\right)$. The set of $n$ relative priorities should be normalized to the sum of one, $\sum_{i=1}^{n} w_{i}=1, w_{i}>0$, $i=1, \cdots, n$. Therefore, the number of independent local priorities is $(n-1)$.

If the matrix of judgments is consistent, there will be several distinct weight vectors, which are true in the following inequality:

$$
\begin{aligned}
l_{i j} \leq \frac{w_{i}}{w_{j}} \leq u_{i j}, \quad i=1, \cdots, n-1 ; \\
j=2, \cdots, n ; \quad i<j .
\end{aligned}
$$

However, if the judgments are incompatible, there will not be any weight vector that simultaneously holds in the above inequality for all the elements of the matrix. Therefore, it is reasonable that, rather than looking for inequalities which hold for all conditions, we can determine the weights in such a way that they hold "as far as possible" in the inequalities. This means that a desirable solution is a solution which makes the above inequality holds for almost all elements of the matrix. We have:

$$
\begin{aligned}
l_{i j} & \widetilde{\leq} \frac{w_{i}}{w_{j}} \widetilde{\leq} u_{i j}, \quad i=1, \cdots, n-1 ; \quad j=2, \cdots, n ; \\
& i<j
\end{aligned}
$$

where $\tilde{\leq}$ indicates "less than or equal to."

In order to solve Ineq. (6), we introduce the following two simple inequality constraints:

$$
\begin{aligned}
& w_{i}-w_{j} u_{i j} \stackrel{\sim}{\leq} 0,
\end{aligned}
$$

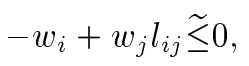

$$
\begin{aligned}
& i=1, \cdots, n-1, \quad j=2, \cdots, n, \quad i<j .
\end{aligned}
$$

The above set of $m$ fuzzy constraints is indicated in the form of a matrix as $R \omega \stackrel{\widetilde{\leq}}{\leq} 0$, where $R \in \Re^{m \times n}$, $m=n(n-1)$.

In order to determine the values of $w_{i}$ and $w_{j}$, the feasible region for the interface of constraints is determined using the minimum or the maximum operator and the solution for the model can be achieved through the minimum-maximum or maximum-minimum approach.

Consider a group with $k$ decision-makers to evaluate $n$ elements (clusters, criteria, sub-criteria, or alternatives). The membership function of the fuzzy linear constraint of the $k$ th row of $R w$, which is defined as $R_{k} w \stackrel{\widetilde{\leq}}{\leq} 0, k=1, \cdots, m$, can be expressed as follows:

$$
\mu_{k}\left(R_{k} \omega\right)= \begin{cases}1 & R_{k} \omega \leq 0 \\ 1-\frac{R_{k} \omega}{d_{k}} & 0 \leq R_{k} \omega \leq d_{k} \\ 0 & R_{k} \omega>d_{k}\end{cases}
$$

where $R_{k}$ denotes the $k$ th row of $R$ and $w$ indicates the priority vector, $w=\left(w_{1}, \cdots, w_{n}\right)^{T}$.

Also, $d_{k}$ indicates the deviation from correctness of the definitive inequality $R_{k} \leq 0$. In fact, it shows the degree of deviation or tolerance of the inequality. High membership function indicates decision-maker satisfaction if a particular weight vector and this satisfaction is, in fact, indicative of the accuracy of the $K$ th constraint in accordance with Eq. (8). If a definite constraint $R_{k} \leq 0$ is severely violated, $\mu_{k}\left(R_{k} \omega\right)$ will be equal to zero. If it is as met as possible, the relationship rises in an approximately linear manner and approaches 1 . Finally, when the equation is fully met, it is larger than 1. The membership function is shown in Figure 2. 


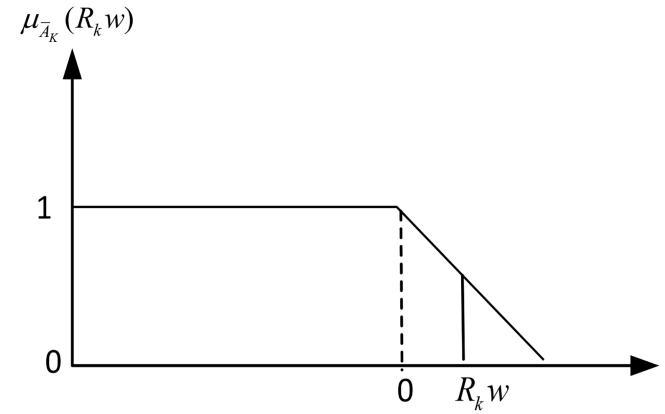

Figure 2. Membership function.

Now, it is necessary first to determine the common feasible region for the constraints and then to identify their optimum points (maximum).

This problem can be solved through the Mikhailov FPP method based on two assumptions as follows [58].

The first assumption requires the existence of a nonempty feasible region $P$ on the $(n-1)$-dimensional simplex $Q^{n-1}$ plane.

$$
Q^{n-1}=\left[\left(w_{1}, \cdots, w_{n}\right) \mid w_{i}>0, \sum_{i=1}^{n} w_{i}=1\right] .
$$

The second assumptions of the FPP method specifies a selection rule, which determines a priority vector with the highest degree of membership in the aggregated membership function.

For the set of constraints in Eq. (7), the membership function of the fuzzy feasible region $\tilde{p}$ is as follows:

$$
\begin{gathered}
\mu_{\tilde{P}}(w)=\min \left[\mu_{1}\left(R_{1} w\right), \cdots, \mu_{m}\left(R_{m} w\right)\right. \\
\left.\mid w_{1}+\cdots+w_{n}=1\right] .
\end{gathered}
$$

According to Eq. (10), each of the membership functions $\mu_{k}\left(R_{k} \omega\right), k=1, \cdots, m$ represents the distance, which can be optimally converted to Eq. (11) by using the infinity norm $L_{\infty}$. More details are included in the appendix. The fuzzy feasible region is defined as an interface of all fuzzy constraints. If the initial judgment matrix is incompatible, in order to avoid an empty region (the state of the absence of a feasible region), the acceptable deviation value $d_{k}$ must be selected sufficiently large.

The feasible region indicates the overall consumer satisfaction of the definitive weight vector. Therefore, a priority vector must be defined at this stage that maximizes the degree of satisfaction.

$\mu_{P}(w)$ is a convex set and since the fuzzy feasible region $\tilde{P}$ and all the fuzzy constraints are convex sets, there is always a point $w^{*}$ in the feasible region that maximizes the degree of membership in $\tilde{P}$.

The first step is to determine the priority vector with the highest degree of membership. A preference vector must be given for the membership functions to maximize the general degree of membership.
The FPP method assumes the priority vector with the highest membership degree. A priority vector must be defined for membership functions in a way that it maximizes the total membership degree.

The maximum solution is a definite weight vector $w_{\max }^{*}$ that gives the maximum fuzzy feasible region:

$$
\begin{gathered}
\mu_{\tilde{P}}\left(w_{\max }^{*}\right)=\max _{w \in Q^{n-1}} \min \left[\mu_{1}\left(R_{1} w\right), \cdots, \mu_{m}\left(R_{m} w\right)\right. \\
\left.\mid w_{1}+\cdots+w_{n}=1\right] .
\end{gathered}
$$

The maximum-minimum fuzzy linear problem can be converted into a definite linear problem. Bellman and Zadeh (1970) proposed the basic decision-making processes in a fuzzy environment. They proposed the maximal-minimal operator to find the maximum solution for decision-making problems with fuzzy goals and constraints, and defined the variable $\alpha$ as follows:

$$
\alpha=\min \left[\mu_{1}\left(R_{1} w\right), \cdots, \mu_{m}\left(R_{m} w\right)\right] .
$$

$R_{k} w$ is the $K$ th row of the fuzzy constraints set of membership functions. Therefore, the objective function to maximize membership functions is as follows:

$$
\max \alpha \text {. }
$$

Here, the variable $\alpha$ indicates the degree of membership of a particular weight vector in the fuzzy feasible region of $\tilde{P}$. In order to solve Eq. (12), it is necessary for $\alpha$ to be smaller than all degrees of membership within the function.

Using Eqs. (8) and (11), the following programming model that represents the degree of membership of the fuzzy feasible region $\tilde{P}$ can be obtained:

$\max \alpha$

$$
\begin{aligned}
& \text { s.t. } d_{k} \alpha+R_{k} w \leq d_{k}, \quad k=1, \cdots, m, \\
& \sum_{i=1}^{n} w_{i}=1, \quad w_{i}>0 \\
& 0 \leq \alpha \leq 1
\end{aligned}
$$

The objective function in terms of membership functions is defined as follows:

$\max \alpha$,

$$
\text { s.t. } \alpha \leq \mu_{k}\left(R_{k} w\right), \quad k=1, \cdots, m \text {. }
$$

The optimal solution for the linear problem is the $\left(w^{*}, \alpha^{*}\right)$ vector. The first component $w^{*}$ is the relative vector, which represents the maximum degree of membership in the fuzzy feasible region, and the second component represents the maximum value of the degree of $\alpha^{*}=\mu_{\tilde{p}}\left(w^{*}\right)$.

Since the fuzzy feasible region $\tilde{P}$ and all the fuzzy constraints are convex sets, there is always a point $w^{*}$ in the feasible region that minimizes the degree of membership in $\tilde{P}$. 
The use of the minimum-maximum operator is a general method for finding solutions to decision problems with fuzzy goals and constraints.

At this stage, a priority vector for nonmembership functions must be defined, which minimizes the total degree of non-membership. Therefore, the vector $w_{\text {min }}^{*}$ should be identified by which the minimum fuzzy feasible region is obtained, that is:

$$
\begin{gathered}
\mu_{\tilde{P}}\left(w_{\min }^{*}\right)=\min _{w \in Q^{n-1}} \max \left[\mu_{1}\left(R_{1} w\right), \cdots, \mu_{m}\left(R_{m} w\right)\right. \\
\left.\mid w_{1}+\cdots+w_{n}=1\right] .
\end{gathered}
$$

In order to obtain the minimizing solution, the variable $\beta$ is defined as follows:

$$
\beta=\max \left\{v_{1}\left(R_{1} w\right), \cdots, v_{m}\left(R_{m} w\right)\right\} .
$$

The non-membership function of the fuzzy linear con-

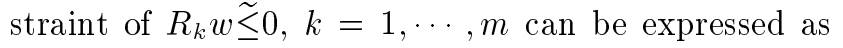
$v_{k}\left(R_{k} w\right)$.

Therefore, the objective function for nonmembership functions is converted into:

$$
\begin{aligned}
& \min \beta, \\
& \text { s.t. } \beta \geq v_{k}\left(R_{k} w\right), \quad k=1, \cdots, m,
\end{aligned}
$$

where $v_{k}$ is the linear non-membership function char-

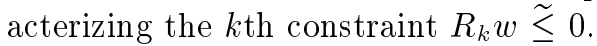

According to the obtained Eqs. (15) and (18) in the two previous steps, the final multi-objective model for both the membership and non-membership constraints will be written as follows:

$$
\begin{aligned}
& \max \alpha, \quad \min \beta, \\
& \text { s.t. } \alpha \leq \mu_{k}\left(R_{k} w\right), \quad \beta \geq v_{k}\left(R_{k} w\right) \\
& \sum_{i=1}^{n} w_{i}=1, \quad k=1, \cdots, m .
\end{aligned}
$$

For solving this model, for each $\alpha$, the minimum model $\left(f_{0}: \min \alpha\right)$ and the maximum model $\left(f_{1}\right.$ : $\max \alpha$ ) are calculated to obtain the maximum and minimum acceptable solutions. Then, the minimum $\left(g_{0}: \min \beta\right)$ and maximum $\left(g_{1}: \max \beta\right)$ models are solved separately to minimize the maximum acceptable solution $\beta$ as follows:

$$
\begin{array}{ll}
f_{0}: & \min \alpha, \\
\text { s.t. } & \alpha \leq \mu_{k}\left(R_{k} w\right), \quad \beta \geq v_{k}\left(R_{k} w\right), \\
& \sum_{i=1}^{n} w_{i}=1, \quad k=1, \cdots, m . \\
f_{1}: & \max \alpha, \\
\text { s.t. } & \alpha \leq \mu_{k}\left(R_{k} w\right), \quad \beta \geq v_{k}\left(R_{k} w\right),
\end{array}
$$

$$
\sum_{i=1}^{n} w_{i}=1, \quad k=1, \cdots, m,
$$

$g_{0}: \min \beta$,

$$
\begin{aligned}
& \text { s.t. } \alpha \leq \mu_{k}\left(R_{k} w\right), \quad \beta \geq v_{k}\left(R_{k} w\right) \text {, } \\
& \sum_{i=1}^{n} w_{i}=1, \quad k=1, \cdots, m, \\
& g_{1}: \max \beta \\
& \text { s.t. } \alpha \leq \mu_{k}\left(R_{k} w\right), \quad \beta \geq v_{k}\left(R_{k} w\right) \text {, } \\
& \sum_{i=1}^{n} w_{i}=1, \quad k=1, \cdots, m .
\end{aligned}
$$

In the following, considering the solutions given for the above models, the membership functions of the two variables $\alpha$ and $\beta$ are obtained as follows:

$$
\begin{aligned}
& \mu_{\alpha}= \begin{cases}0 & \text { if } \quad \alpha \leq f_{0(\alpha)} \\
\frac{\alpha-f_{0(\alpha)}}{f_{1(\alpha)}-f_{0(\alpha)}} & \text { if } \quad f_{0(\alpha)} \leq \alpha \leq f_{1(\alpha)} \\
1 & \text { if } \quad \alpha \geq f_{1(\alpha)}\end{cases} \\
& \mu_{\beta}=\left\{\begin{array}{lll}
1 & \text { if } \quad \beta \leq g_{0} \\
\frac{g_{1}-\beta}{g_{1}-g_{0}} & \text { if } \quad g_{0} \leq \beta \leq g_{1} \\
0 & \text { if } \quad \beta \geq g_{1}
\end{array}\right.
\end{aligned}
$$

According to the above membership functions, a maximal solution in terms of a definite weight vector $w^{*}$, which leads to the maximum fuzzy acceptable region, is defined as follows:

$$
\mu_{\bar{P}}\left(w^{*}\right)=\max \left\{\min \left(\mu_{\alpha}, \mu_{\beta}\right)\right\} .
$$

A model for the membership functions is defined using the maximum-minimum operator, wherein the variable $\theta$ is assumed as follows:

$$
\theta=\min \left(\mu_{\alpha}, \mu_{\beta}\right) \text {. }
$$

Therefore, the objective function for the membership functions can be converted into Eq. (28):

$\max \theta$,

$$
\text { s.t. } \theta \leq \mu_{\alpha} \quad \theta \leq \mu_{\beta} .
$$

The final model using the membership and nonmembership functions will be as follows:

$\max \theta$,

s.t.

$\alpha-\theta\left(f_{1}-f_{0}\right) \geq f_{0}$

$\beta+\theta\left(g_{1}-g_{0}\right) \leq g_{1}$,

$\alpha w_{j}\left(m_{i j}-l_{i j}\right)-\left(w_{i}-l_{i j} w_{j}\right) \delta_{i j} \leq 0 ;$ 


$$
\begin{aligned}
& \alpha w_{j}\left(u_{i j}-m_{i j}\right)-\left(u_{i j} w_{j}-w_{i}\right) \delta_{i j} \leq 0 ; \\
& m_{i j} w_{j}-w_{i}+\left(w_{i}-l_{i j} w_{j}\right) \varepsilon_{i j}-\beta w_{j}\left(m_{i j}-l_{i j}\right) \leq 0 \\
& w_{i}-m_{i j} w_{j}+\left(u_{i j} w_{j}-w_{i}\right) \varepsilon_{i j}-\beta w_{j}\left(u_{i j}-m_{i j}\right) \leq 0 \\
& w_{1}+\cdots+w_{n}=1 ; \\
& w_{1}, \cdots, w_{n}>0 ; \\
& i=1, \cdots, n-1 ; \quad j=2, \cdots, n ; \quad i<j .
\end{aligned}
$$

Eq. (29) is a nonlinear model. Therefore, achieving a solution to the equation is not possible using the Simplex method and it should be solved by employing the appropriate methods and software such as lingo.

\subsection{Network DEA}

Although almost all organizations have a hierarchical structure, due attention has been paid to such systems. An organization usually has several units at the first level and several subunits at the second level. In case the subunits are large, there may also be several subsubunits with different functions at the third level and this leveling can continue if necessary. At the highest level, that is, level 0 , the input is distributed to the subset units at the first level. Similarly, each unit at the first level distributes the input to its subset units at the second level. Suppose there is a system as in Figure 3.

In the hierarchy system studied, each DMU has the same number of units at the first level with separate running functions. At the first level, if a unit has subunits at a lower level, then the other DMUs must have the same number of subunits with similar running functions so that a DMU has a one-to-one correspondence in units with other DMUs.
The system is named according to this rule. Level 0 is known as the highest one, which has four subunits of one, two, three, and four at the first level. Each subunit in the first level has two subunits at the lower level. Subunit 1 has two subunits $(1,1)$ and $(1,2)$; subunit 2 has two subunits $(2,1)$ and $(2,2)$; subunit 3 has two subunits $(3,1)$ and $(3,2)$; and subunit 4 has two subunits $(4,1)$ and $(4,2)$. It should be noted that subunits of one level do not have to have the same number of sub-subunit and they can have any sub-subunits.

Suppose that there are $n$ DMUs with a similar structure to measure comparable efficiency. $X_{i j}^{(p)}$ and $Y_{r j}^{(p)}$ are the $i$ th input and the $r$ th output of $D M U_{j}$ for unit $p$, respectively. This system uses $m$ inputs to generate $s$ outputs. The input is divided into two categories of shared and specific, while the output is specific. In the hierarchical system method, the top management of the organization assigns input to the first level for the division into lower levels. Then, the input assigned to the first level is divided at the second level. The input allocation process continues in this way up to the last level (the lowest level). The output divided at the lowest level is what has been generated. Each unit has a specific input. It is assumed that the shared input is $x_{i}, i=1, \cdots, n$; then, $\alpha_{i} x_{i}$ is distributed to unit $1, \beta_{i} x_{i}$ to unit $2, \gamma_{i} x_{i}$ to unit 3 , and $\delta_{i} x_{i}$ to unit 4 so that $\sum_{i=1}^{n}\left(\alpha_{i}+\beta_{i}+\gamma_{i}+\delta_{i}\right)=1$. In fact, the input entered in unit 1 is equal to the sum of the specific and shared input. That is, the input to unit 1 is equal to $\alpha_{i} x_{i}+x^{(1)}$, the input to unit 2 is equal to $\alpha_{i} x_{i}+x^{(2)}$, the input to unit 3 is equal to $\alpha_{i} x_{i}+x^{(3)}$, and the input to unit 4 is equal to $\alpha_{i} x_{i}+x^{(4)}$. Each unit at different levels does not consume all $m$ inputs and does not generate the total $s$ outputs. It distributes its own input from its parent into its subunits in order to

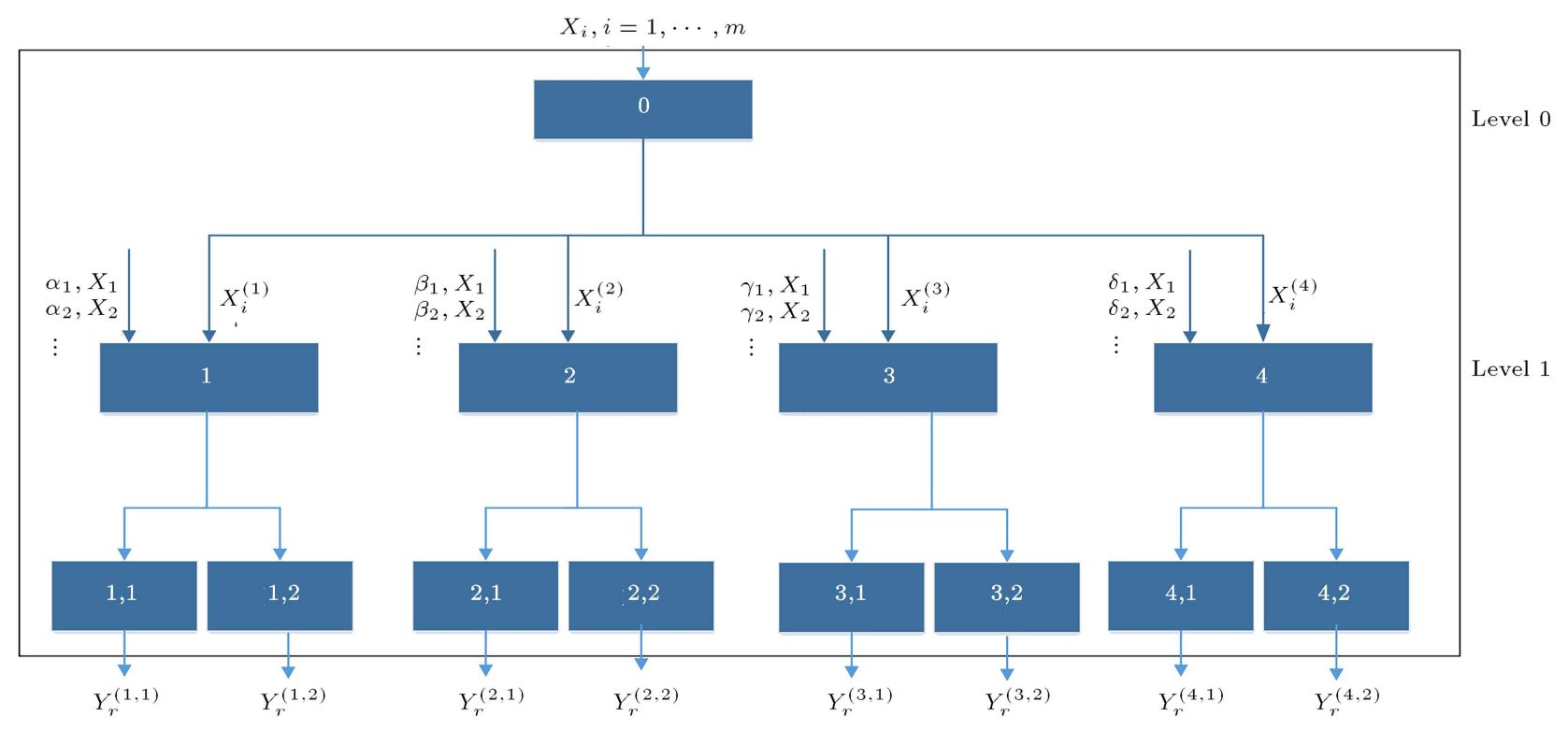

Figure 3. Hierarchical system. 


$$
E_{K}^{B B}=\max \frac{\sum_{r=1}^{s} u_{r}\left(Y_{r k}^{(1,1)}+Y_{r k}^{(1,2)}+Y_{r k}^{(2,1)}+Y_{r k}^{(2,2)}+Y_{r k}^{(3,1)}+Y_{r k}^{(3,2)}+Y_{r k}^{(4,1)}+Y_{r k}^{(4,2)}\right)}{\sum_{i=1}^{m} v_{i} X_{i k}},
$$

s.t.

$$
\begin{gathered}
\sum_{r=1}^{s} u_{r}\left(Y_{r k}^{(1,1)}+Y_{r k}^{(1,2)}+Y_{r k}^{(2,1)}+Y_{r k}^{(2,2)}+Y_{r k}^{(3,1)}+Y_{r k}^{(3,2)}+Y_{r k}^{(4,1)}+Y_{r k}^{(4,2)}\right)-\sum_{i=1}^{m} v_{i} X_{i j} \leq 0 \\
j=1, \cdots, n ; \quad u_{r}, v_{i} \geq \varepsilon ; \quad r=1, \cdots, s ; \quad i=1, \cdots, m .
\end{gathered}
$$

Box I

generate output. For example, unit (1) receives shared input $\alpha_{i} x_{i}$ from the parent unit (0) and has its specific input $x^{(1)}$ as well.

The traditional black box DEA model focuses on the coefficients $u_{r}$ and $v_{i}$ to generate the highest ratio of integrated share of outputs generated by the evaluation of the DMU to the total inputs employed given that the ratio for each DMU should be less than or equal to one. In practice, the black box efficiency $\left(E_{B B}\right)$ measurement model $D M U_{K}$ with the assumption of constant returns to scale is expressed by Eq. (30), as shown in Box I. If the internal operations of the hierarchical system units are considered, then network efficiency $\left(E^{N W}\right)$ can be measured. Since this system has four subunits at different levels, there will be four constraint sets in the network model. By maximizing the efficiency of the DMU, in unit (0) at level (0), the objective function is as follows:

$$
E_{k}^{N W}=\max \frac{\sum_{r=1}^{s} u_{r} Y_{r k}}{\sum_{i=1}^{m} v_{i} X_{i k}}
$$

s.t.

Unit $(0): \sum_{r=1}^{s} u_{r} Y_{r j}-\sum_{i=1}^{m} v_{i} X_{i j} \leq 0$

$$
j=1, \cdots, n,
$$

$\operatorname{Unit}(1): \sum_{r=1}^{s} u_{r} Y_{r j}^{(1)}-\sum_{i=1}^{m} v_{i}\left(X_{i j}^{(1)}+\alpha_{i j} X_{i j}\right) \leq 0$

$$
j=1, \cdots, n
$$

$\operatorname{Unit}(2): \sum_{r=1}^{s} u_{r} Y_{r j}^{(2)}-\sum_{i=1}^{m} v_{i}\left(X_{i j}^{(2)}+\beta_{i j} X_{i j}\right) \leq 0$

$$
j=1, \cdots, n,
$$

$$
\begin{gathered}
\operatorname{Unit}(3): \sum_{r=1}^{s} u_{r} Y_{r j}^{(3)}-\sum_{i=1}^{m} v_{i}\left(X_{i j}^{(3)}+\gamma_{i j} X_{i j}\right) \leq 0 \\
j=1, \cdots, n \\
\text { Unit (4): } \sum_{r=1}^{s} u_{r} Y_{r j}^{(4)}-\sum_{i=1}^{m} v_{i}\left(X_{i j}^{(4)}+\delta_{i j} X_{i j}\right) \leq 0 \\
\quad j=1, \cdots, n, \\
u_{r}, v_{i} \geq \varepsilon, \quad r=1, \cdots, s, \quad i=1, \cdots, m .
\end{gathered}
$$

such that:

$$
\begin{aligned}
& Y_{r j}^{(1)}=Y_{r j}^{(1,1)}+Y_{r j}^{(1,2)}, \\
& Y_{r j}^{(2)}=Y_{r j}^{(2,1)}+Y_{r j}^{(2,2)}, \\
& Y_{r j}^{(3)}=Y_{r j}^{(3,1)}+Y_{r j}^{(3,2)}, \\
& Y_{r j}^{(4)}=Y_{r j}^{(4,1)}+Y_{r j}^{(4,2)} .
\end{aligned}
$$

The objective function is nonlinear, but it can be converted into a linear form by assigning a value of 1 to a denominator and can be eliminated from the numerator of the objective function.

$$
\begin{aligned}
& E_{k}^{N W}=\max \sum_{r=1}^{s} u_{r} Y_{r k}, \\
& \text { s.t. } \sum_{i=1}^{m} v_{i} X_{i k}=1,
\end{aligned}
$$

Unit (0): $\sum_{r=1}^{s} u_{r} Y_{r j}-\sum_{i=1}^{m} v_{i} X_{i j} \leq 0$,

$$
j=1, \cdots, n,
$$

$\operatorname{Unit}(1): \sum_{r=1}^{s} u_{r} Y_{r j}^{(1)}-\sum_{i=1}^{m} v_{i}\left(X_{i j}^{(1)}+\alpha_{i j} X_{i j}\right) \leq 0$, 


$$
j=1, \cdots, n
$$

Unit (2): $\sum_{r=1}^{s} u_{r} Y_{r j}^{(2)}-\sum_{i=1}^{m} v_{i}\left(X_{i j}^{(2)}+\beta_{i j} X_{i j}\right) \leq 0$

$$
j=1, \cdots, n,
$$

$\operatorname{Unit}(3): \sum_{r=1}^{s} u_{r} Y_{r j}^{(3)}-\sum_{i=1}^{m} v_{i}\left(X_{i j}^{(3)}+\gamma_{i j} X_{i j}\right) \leq 0$,

$$
j=1, \cdots, n,
$$

Unit (4): $\sum_{r=1}^{s} u_{r} Y_{r j}^{(4)}-\sum_{i=1}^{m} v_{i}\left(X_{i j}^{(4)}+\delta_{i j} X_{i j}\right) \leq 0$,

$$
j=1, \cdots, n,
$$

$$
u_{r}, v_{i} \geq \varepsilon, \quad r=1, \cdots, s, \quad i=1, \cdots, m .
$$

Network model (32) includes additional constraints. The sum of the constraints corresponding to units (1), (2), (3), and (4) is similar to the parent unit (0). Thus, the constraints corresponding to unit (0) are additional and can be eliminated.

$$
\begin{aligned}
& E_{k}^{N W}=\max \sum_{r=1}^{s} u_{r} Y_{r k}, \\
& \text { s.t. } \sum_{i=1}^{m} v_{i} X_{i k}=1,
\end{aligned}
$$

Unit (1): $\sum_{r=1}^{s} u_{r} Y_{r j}^{(1)}-\sum_{i=1}^{m} v_{i}\left(X_{i j}^{(1)}+\alpha_{i j} X_{i j}\right) \leq 0$,

$$
j=1, \cdots, n,
$$

Unit (2): $\sum_{r=1}^{s} u_{r} Y_{r j}^{(2)}-\sum_{i=1}^{m} v_{i}\left(X_{i j}^{(2)}+\beta_{i j} X_{i j}\right) \leq 0$,

$$
j=1, \cdots, n,
$$

Unit (3): $\sum_{r=1}^{s} u_{r} Y_{r j}^{(3)}-\sum_{i=1}^{m} v_{i}\left(X_{i j}^{(3)}+\gamma_{i j} X_{i j}\right) \leq 0$,

$$
j=1, \cdots, n,
$$

Unit (4): $\sum_{r=1}^{s} u_{r} Y_{r j}^{(4)}-\sum_{i=1}^{m} v_{i}\left(X_{i j}^{(4)}+\delta_{i j} X_{i j}\right) \leq 0$,

$$
j=1, \cdots, n,
$$

$u_{r}, v_{i} \geq \varepsilon, \quad r=1, \cdots, s, \quad i=1, \cdots, m$.

\section{IFANP-NDEA method}

Management in many organizations has a hierarchical

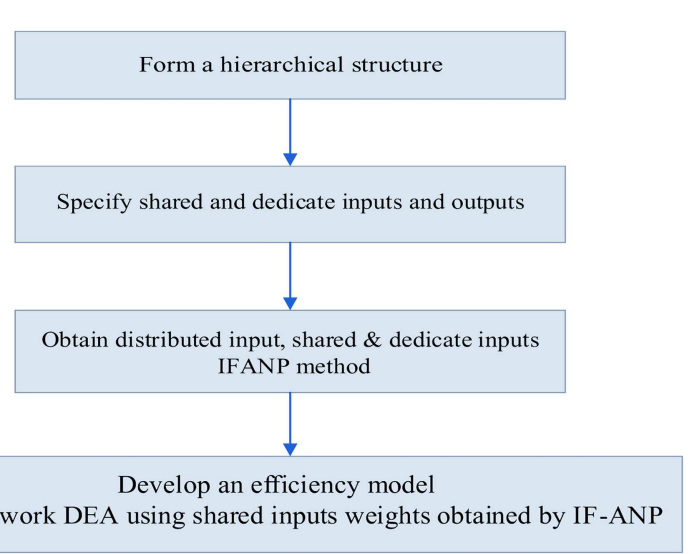

Figure 4. Methodology algorithm.

structure. DEA method has a general disadvantage due to its merely mathematical nature and hence, not incorporating qualitative, inferential, and intuitive indicators. However, this disadvantage can be resolved by some MCDM techniques, including ANP, due to their specific characteristics. In practice, both DEA and ANP methods are used. Both models have their own limitations, but their combination gains benefits of both and tackles their limitations.

The framework of the present study consists of four steps as shown in Figure 4. The Faculty of Basic Sciences of the Islamic Azad University is investigated. Education and research are the two main functions of a university. In many cases, the system consists of several parallel processes; for example, a university includes departments that use multiple inputs to generate multiple outputs. The Charnes, Cooper, and Rhodes (CCR) model can be used to measure the efficiency of a university [11]. If the decision-maker is interested in the performance of a particular department, the model is applicable to the inputs and outputs of the respective department. Theoretically, if all the components of a processes are efficient, the system will be efficient. However, it is possible to design examples that are inconsistent with this assumption in order to evaluate the efficiency of the system and its processes independently. DEA investigates a system as a black box and ignores the internal relations of the processes. The NDEA model is an approach to evaluating the efficiency of systems with several processes and it is able to deal with the processes and the internal relations. The main goal of the NDEA research is to open the black box of a system. It includes the elements of components when computing the efficiency. Figure 5 shows the structure of the Faculty of Basic Sciences with inputs and outputs.

The Faculty of Basic Sciences includes the departments of mathematics, biology, chemistry, and physics. The university can be studied from different aspects of research, educational, administrative, financial, student, and cultural. Each group can be investigated in terms of education and research dimensions. 


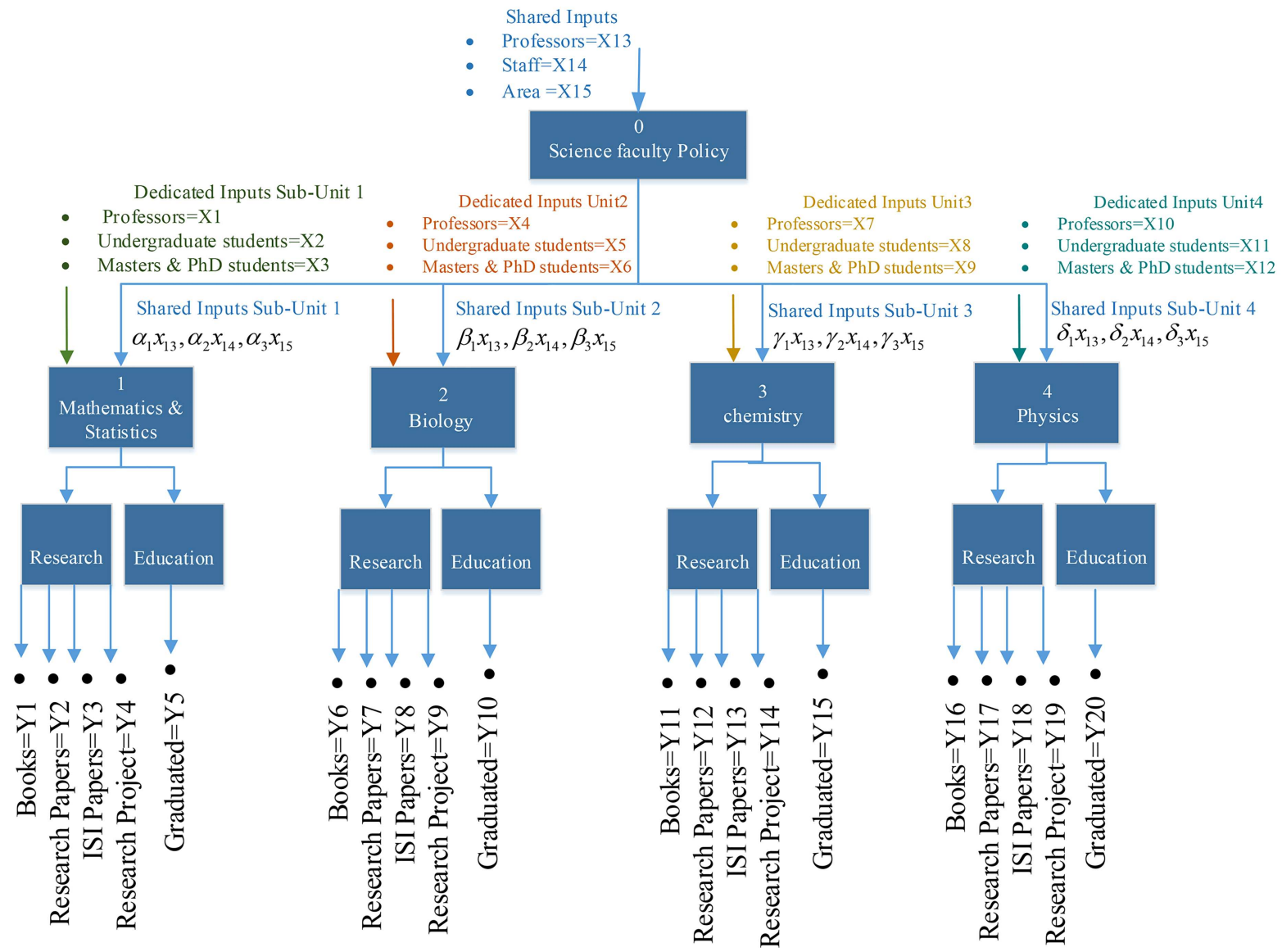

Figure 5. DMU structure with input and output.

Each group has three specific inputs and three shared inputs. Specific inputs include specialized professors as well as bachelor's, and master's and $\mathrm{PhD}$ students. Shared inputs include general professors, staff, and area. The research outcomes of each group include books, research papers, ISI articles, and research projects and the educational outcome is graduation. In the present study, there are 9 DMUs. Table 1 presents information on the DMUs.

Since the number of DMUs is less than three multiplied by the sum of the inputs and outputs and, in fact, the relation $n \geq 3(m+s)$ is not met, weight limitations should be applied by the experts. The measurement model of network efficiency $D M U_{K}$ with the assumption of constant returns to scale is as follows:

$$
\begin{aligned}
E_{k}^{N W}= & \max u_{1} Y_{1 k}+u_{2} Y_{2 k}+u_{3} Y_{3 k}+u_{4} Y_{4 k} \\
& +u_{5} Y_{5 k}+u_{6} Y_{6 k}+u_{7} Y_{7 k}+u_{8} Y_{8 k}+u_{9} Y_{9 k} \\
& +u_{10} Y_{10 k}+u_{11} Y_{11 k}+u_{12} Y_{12 k}+u_{13} Y_{13 k} \\
& +u_{14} Y_{14 k}+u_{15} Y_{15 k}+u_{16} Y_{16 k}+u_{17} Y_{17 k} \\
& +u_{18} Y_{18 k}+u_{19} Y_{19 k}+u_{20} Y_{20 k}
\end{aligned}
$$

s.t.

$$
\begin{aligned}
v_{1} X_{1 k} & +v_{2} X_{2 k}+v_{3} X_{3 k}+v_{4} X_{4 k}+v_{5} X_{5 k}+v_{6} X_{6 k} \\
& +v_{7} X_{7 k}+v_{8} X_{8 k}+v_{9} X_{9 k}+v_{10} X_{10 k} \\
& +v_{11} X_{11 k}+v_{12} X_{12 k}+v_{13} X_{13 k} \\
& +v_{14} X_{14 k}+v_{14} X_{14 k}+v_{15} X_{15 k}=1, \\
\left(u_{1} Y_{1 j}\right. & \left.+u_{2} Y_{2 j}+u_{3} Y_{3 j}+u_{4} Y_{4 j}\right)+u_{5} Y_{5 j} \\
& -\left(v_{1} X_{1 j}+v_{2} X_{2 j}+v_{3} X_{3 j}\right) \\
& -\left(\alpha_{1} v_{13} X_{13 j}+\alpha_{2} v_{14} X_{14 j}+\alpha_{3} v_{15} X_{15 j}\right) \leq 0, \\
\left(u_{6} Y_{6 j}\right. & \left.+u_{7} Y_{7 j}+u_{8} Y_{8 j}+u_{9} Y_{9 j}\right)+u_{10} Y_{10 j} \\
& -\left(v_{4} X_{4 j}+v_{6} X_{6 j}+v_{7} X_{7 j}\right) \\
& -\left(\beta_{1} v_{13} X_{13 j}+\beta_{2} v_{14} X_{14 j}+\beta_{3} v_{15} X_{15 j}\right) \leq 0 \\
\left(u_{11} Y_{11 j}\right. & \left.+u_{12} Y_{12 j}+u_{13} Y_{13 j}+u_{14} Y_{14 j}\right) \\
+ & u_{15} Y_{15 j}-\left(v_{8} X_{8 j}+v_{9} X_{9 j}+v_{10} X_{10 j}\right) \\
- & \left(\gamma_{1} v_{13} X_{13 j}+\gamma_{2} v_{14} X_{14 j}+\gamma_{3} v_{15} X_{15 j}\right) \leq 0,
\end{aligned}
$$


Table 1. Information for DMUs.

\begin{tabular}{|c|c|c|c|c|c|c|}
\hline 2015-2016 & Input and output & Mean & $\begin{array}{l}\text { Variance of } \\
\text { the entire } \\
\text { population } \\
\text { (Var.p) }\end{array}$ & $\begin{array}{c}\text { Variance of } \\
\text { a sample } \\
\text { set of data } \\
\text { (Var.s) }\end{array}$ & $\begin{array}{c}\text { Standard } \\
\text { deviation of } \\
\text { the entire } \\
\text { population } \\
\text { (Std.p) }\end{array}$ & $\begin{array}{c}\text { Standard } \\
\text { deviation of } \\
\text { a sample } \\
\text { set of data } \\
\text { (Std.s) }\end{array}$ \\
\hline \multirow{8}{*}{ 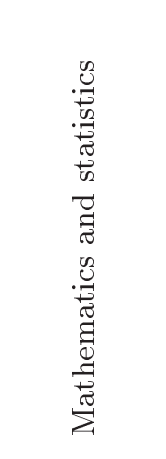 } & $X_{1}=$ Specialized faculty members & 22 & 41 & 46 & 6 & 7 \\
\hline & $X_{2}=$ Undergraduate students & 211 & 24081 & 27091 & 155 & 165 \\
\hline & $X_{3}=$ Master's and PhD students & 261 & 8559 & 9629 & 93 & 98 \\
\hline & $Y_{1}=$ Books & 4 & 1 & 1 & 1 & 1 \\
\hline & $Y_{2}=$ Research papers & 26 & 76 & 85 & 9 & 9 \\
\hline & $\begin{aligned} Y_{3}= & \text { International Scientific Indexing } \\
& (\text { ISI }) \text { papers }\end{aligned}$ & 10 & 27 & 30 & 5 & 5 \\
\hline & $Y_{4}=$ Research projects & 59 & 668 & 752 & 26 & 27 \\
\hline & $Y_{5}=$ Graduated students & 171 & 2434 & 2738 & 49 & 52 \\
\hline \multirow{8}{*}{$\begin{array}{l}\overrightarrow{00} \\
\stackrel{0}{0} \\
\stackrel{0}{0}\end{array}$} & $X_{4}=$ Specialized faculty members & 23 & 76 & 86 & 9 & 9 \\
\hline & $X_{5}=$ Undergraduate students & 524 & 49498 & 55685 & 222 & 236 \\
\hline & $X_{6}=$ Master's and PhD students & 354 & 9449 & 10630 & 97 & 103 \\
\hline & $Y_{6}=$ Books & 3 & 4 & 4 & 2 & 2 \\
\hline & $Y_{7}=$ Research papers & 44 & 406 & 457 & 20 & 21 \\
\hline & $Y_{8}=$ ISI papers & 42 & 239 & 269 & 15 & 16 \\
\hline & $Y_{9}=$ Research projects & 47 & 488 & 550 & 22 & 23 \\
\hline & $Y_{10}=$ Graduated students & 210 & 4508 & 5071 & 67 & 71 \\
\hline \multirow{8}{*}{ 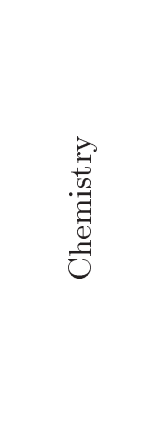 } & $X_{7}=$ Specialized faculty members & 28 & 178 & 201 & 13 & 14 \\
\hline & $X_{8}=$ Undergraduate students & 451 & 41368 & 46539 & 203 & 216 \\
\hline & $X_{9}=$ Master's and PhD students & 167 & 4126 & 4641 & 64 & 68 \\
\hline & $Y_{11}=$ Books & 3 & 3 & 4 & 2 & 2 \\
\hline & $Y_{12}=$ Research papers & 15 & 22 & 25 & 5 & 5 \\
\hline & $Y_{13}=$ ISI papers & 39 & 103 & 116 & 10 & 11 \\
\hline & $Y_{14}=$ Research projects & 48 & 722 & 812 & 27 & 28 \\
\hline & $Y_{15}=$ Graduated students & 55 & 339 & 382 & 18 & 20 \\
\hline \multirow{8}{*}{$\frac{\underbrace{n}_{\tilde{n}}}{\sum_{n}^{n}}$} & $X_{10}=$ Specialized faculty members & 59 & 224 & 252 & 15 & 16 \\
\hline & $X_{11}=$ Undergraduate students & 580 & 22938 & 25805 & 151 & 161 \\
\hline & $X_{12}=$ Master's and PhD students & 226 & 6223 & 7001 & 79 & 84 \\
\hline & $Y_{16}=$ Books & 2 & 1 & 2 & 1 & 1 \\
\hline & $Y_{17}=$ Research papers & 5 & 1 & 1 & 1 & 1 \\
\hline & $Y_{18}=$ ISI papers & 49 & 220 & 248 & 15 & 16 \\
\hline & $Y_{19}=$ Research projects & 323 & 14200 & 15975 & 119 & 126 \\
\hline & $Y_{20}=$ Graduated students & 365 & 11061 & 12443 & 105 & 112 \\
\hline \multirow{3}{*}{ 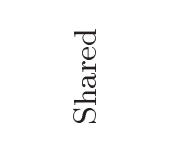 } & $X_{13}=$ General teachers & 28 & 176 & 198 & 13 & 14 \\
\hline & $X_{14}=$ Staff & 38 & 227 & 255 & 15 & 16 \\
\hline & $X_{15}=$ Area & 538 & 51407 & 57833 & 227 & 240 \\
\hline
\end{tabular}




$$
\begin{aligned}
& \left(u_{16} Y_{16 j}+u_{17} Y_{17 j}+u_{18} Y_{18 j}+u_{19} Y_{19 j}\right) \\
& +u_{20} Y_{20 j}-\left(v_{10} X_{10 j}+v_{11} X_{11 j}+v_{12} X_{12 j}\right) \\
& \quad-\left(\delta_{1} v_{13} X_{13 j}+\delta_{2} v_{14} X_{14 j}+\delta_{3} v_{15} X_{15 j}\right) \leq 0 \\
& u_{1}, \cdots, u_{20} \geq 0 ; \quad v_{1}, \cdots, v_{15} \geq 0 .
\end{aligned}
$$

As shown in the above model, $\alpha_{i}, \beta_{i}, \gamma_{i}, \delta_{i}, i=1,2,3$ is the distributed input coefficient to each unit. The value of distributed input to each unit is obtained by the IFANP method.

\subsection{Calculation of the weights of shared inputs through the IFANP}

In this step, the matrix of the paired comparisons should be created. Using Table 2, linguistic variables are converted into triangular fuzzy numbers.

The model has three shared inputs named $x_{13}$, $x_{14}$, and $x_{15}$. It is necessary to calculate each coefficient of shared input that is distributed to each unit. The intuitionistic fuzzy paired comparisons are employed to calculate the distribution coefficient. A matrix of paired comparisons was made by a survey of 10 experts. Suppose $X$ is a set of all the experts who participated in the survey.

$A(x) \quad$ The number of experts who agree;

$D(x) \quad$ The number of experts who disagree;

$U(x) \quad$ The number of experts who neither agree nor disagree (no decision).

Suppose that $n$ is the total number of experts who participated in the survey. We have:

$$
\begin{aligned}
& \mu(x)=\frac{A(x)}{n} ; \quad \nu(x)=\frac{D(x)}{n} ; \\
& \pi(x)=1-\frac{A(x)}{n}-\frac{D(x)}{n}=\frac{n-A(x)-D(x)}{n} .
\end{aligned}
$$

Table 3 shows the results of the survey of experts for the paired comparisons with the groups for input $x_{13}$.

As an instance, for input $x_{13}$, regarding the comparison between the group of biology and the mathematical group, 16 people agreed, shown with the symbol $A(x)$; two experts did not agree, represented by the symbol $D(x)$; and two experts did not participate in voting, indicated by the symbol $U(x)$.

The intuitionistic indicators of certainty, uncertainty, and hesitancy are calculated by the above formula. The results are shown in Table 4 . For example, the certainty degree of 0.6 is calculated as follows:

$$
\mu(x)=\frac{6}{10}=0.6 \text {. }
$$

The global weight of each input distributed to each group is given in Table 5 .

Given the hierarchical structure, the sum of weights is equal to 1 .

$$
\begin{aligned}
& \alpha_{1}+\alpha_{2}+\alpha_{3}+\beta_{1}+\beta_{2}+\beta_{3}+\gamma_{1}+\gamma_{2}+\gamma_{3} \\
& +\delta_{1}+\delta_{2}+\delta_{3}=1 .
\end{aligned}
$$

\begin{tabular}{|c|c|c|c|c|c|c|c|c|c|c|c|c|}
\hline \multirow{2}{*}{$x_{13}$} & \multicolumn{3}{|c|}{ Mathematics } & \multicolumn{3}{|c|}{ Biology } & \multicolumn{3}{|c|}{ Chemistry } & \multicolumn{3}{|c|}{ Physics } \\
\hline & $A(x)$ & $D(x)$ & $U(x)$ & $A(x)$ & $D(x)$ & $U(x)$ & $A(x)$ & $D(x)$ & $U(x)$ & $A(x)$ & $D(x)$ & $U(x)$ \\
\hline Mathematics & & & & 6 & 3 & 1 & 6 & 2 & 2 & 6 & 2 & 2 \\
\hline Biology & 6 & 3 & 1 & & & & 6 & 3 & 1 & 6 & 2 & 2 \\
\hline Chemistry & 6 & 2 & 2 & 6 & 3 & 1 & & & & 6 & 3 & 1 \\
\hline Physics & 6 & 2 & 2 & 6 & 2 & 2 & 6 & 3 & 1 & & & \\
\hline
\end{tabular}

The second stage is about using the weights obtained by the IFANP in the NDEA model. The IFANP-NDEA model is as follows:

Table 2. Triangular fuzzy scale.

\begin{tabular}{lcc}
\hline \multicolumn{1}{c}{ Linguistic scale for importance } & Triangular fuzzy scale & Triangular fuzzy reciprocal scale \\
\hline Just equal & $(1,1,1)$ & $(1,1,1)$ \\
Equally Important (EI) & $(1 / 2,1,3 / 2)$ & $(2 / 3,1,2)$ \\
Weakly More Important (WMI) & $(1,3 / 2,2)$ & $(1 / 2,2 / 3,1)$ \\
Strongly More Important (SMI) & $(3 / 2,2,5 / 2)$ & $(2 / 5,1 / 2,2 / 3)$ \\
Very Strongly More Important (VSMI) & $(2,5 / 2,3)$ & $(1 / 3,2 / 5,1 / 2)$ \\
Absolutely More Important (AMI) & $(5 / 2,3,7 / 2)$ & $(2 / 7,1 / 3,2 / 5)$ \\
\hline
\end{tabular}

Table 3. Paired comparisons of the groups for input $x_{13}$. 
Table 4. Certainty, uncertainty, and hesitancy degrees.

\begin{tabular}{|c|c|c|c|c|c|c|c|c|c|c|c|c|}
\hline \multirow{2}{*}{$x_{13}$} & \multicolumn{3}{|c|}{ Mathematics } & \multicolumn{3}{|c|}{ Biology } & \multicolumn{3}{|c|}{ Chemistry } & \multicolumn{3}{|c|}{ Physics } \\
\hline & $\mu(x)$ & $\nu(x)$ & $\pi(x)$ & $\mu(x)$ & $\nu(x)$ & $\pi(x)$ & $\mu(x)$ & $\nu(x)$ & $\pi(x)$ & $\mu(x)$ & $\nu(x)$ & $\pi(x)$ \\
\hline Mathematics & & & & 0.6 & 0.3 & 0.1 & 0.6 & 0.2 & 0.2 & 0.6 & 0.2 & 0.2 \\
\hline Biology & 0.6 & 0.3 & 0.1 & & & & 0.6 & 0.3 & 0.1 & 0.6 & 0.2 & 0.2 \\
\hline Chemistry & 0.6 & 0.2 & 0.2 & 0.6 & 0.3 & 0.1 & & & & 0.6 & 0.3 & 0.1 \\
\hline Physics & 0.6 & 0.2 & 0.2 & 0.6 & 0.2 & 0.2 & 0.6 & 0.3 & 0.1 & & & \\
\hline
\end{tabular}

Table 5. Global weights.

\begin{tabular}{|c|c|c|c|c|}
\hline & \multicolumn{3}{|c|}{ Groups } \\
\hline & & $X_{13}$ & $X_{14}$ & $X_{15}$ \\
\hline \multirow{4}{*}{$\begin{array}{l}\stackrel{\infty}{*} \\
\stackrel{\Xi}{\Xi} \\
=\end{array}$} & Mathematics & $\alpha_{1}=0.067$ & $\alpha_{2}=0.119$ & $\alpha_{3}=0.098$ \\
\hline & Biology & $\beta_{1}=0.067$ & $\beta_{2}=0.079$ & $\beta_{3}=0.080$ \\
\hline & Chemistry & $\gamma_{1}=0.084$ & $\gamma_{2}=0.079$ & $\gamma_{3}=0.081$ \\
\hline & Physics & $\delta_{1}=0.066$ & $\delta_{2}=0.079$ & $\delta_{3}=0.098$ \\
\hline
\end{tabular}

$$
\begin{aligned}
E_{k}^{N W}= & \max u_{1} Y_{1 k}+u_{2} Y_{2 k}+u_{3} Y_{3 k}+u_{4} Y_{4 k} \\
& +u_{5} Y_{5 k}+u_{6} Y_{6 k}+u_{7} Y_{7 k}+u_{8} Y_{8 k} \\
& +u_{9} Y_{9 k}+u_{10} Y_{10 k}+u_{11} Y_{11 k} \\
& +u_{12} Y_{12 k}+u_{13} Y_{13 k}+u_{14} Y_{14 k} \\
& +u_{15} Y_{15 k}+u_{16} Y_{16 k}+u_{17} Y_{17 k} \\
& +u_{18} Y_{18 k}+u_{19} Y_{19 k}+u_{20} Y_{20 k},
\end{aligned}
$$

s.t.

$$
\begin{aligned}
v_{1} X_{1 k} & +v_{2} X_{2 k}+v_{3} X_{3 k}+v_{4} X_{4 k}+v_{5} X_{5 k} \\
& +v_{6} X_{6 k}+v_{7} X_{7 k}+v_{8} X_{8 k}+v_{9} X_{9 k} \\
& +v_{10} X_{10 k}+v_{11} X_{11 k}+v_{12} X_{12 k}+v_{13} X_{13 k} \\
& +v_{14} X_{14 k}+v_{14} X_{14 k}+v_{15} X_{15 k}=1, \\
\left(u_{1} Y_{1 j}\right. & \left.+u_{2} Y_{2 j}+u_{3} Y_{3 j}+u_{4} Y_{4 j}\right)+u_{5} Y_{5 j} \\
& -\left(v_{1} X_{1 j}+v_{2} X_{2 j}+v_{3} X_{3 j}\right) \\
& -\left(0.067 * v_{13} X_{13 j}+0.119 * v_{14} X_{14 j}\right. \\
& \left.+0.098 * v_{15} X_{15 j}\right) \leq 0, \\
\left(u_{6} Y_{6 j}\right. & \left.+u_{7} Y_{7 j}+u_{8} Y_{8 j}+u_{9} Y_{9 j}\right)+u_{10} Y_{10 j} \\
& -\left(v_{4} X_{4 j}+v_{6} X_{6 j}+v_{7} X_{7 j}\right) \\
& -\left(0.067 * v_{13} X_{13 j}+0.079 * v_{14} X_{14 j}\right. \\
& \left.+0.080 * v_{15} X_{15 j}\right) \leq 0,
\end{aligned}
$$

$$
\begin{aligned}
& \left(u_{11} Y_{11 j}+u_{12} Y_{12 j}+u_{13} Y_{13 j}+u_{14} Y_{14 j}\right) \\
& +u_{15} Y_{15 j}-\left(v_{8} X_{8 j}+v_{9} X_{9 j}+v_{10} X_{10 j}\right) \\
& -\left(0.084 * v_{13} X_{13 j}+0.079 * v_{14} X_{14 j}\right. \\
& \left.+0.081 * v_{15} X_{15 j}\right) \leq 0, \\
& \left(u_{16} Y_{16 j}+u_{17} Y_{17 j}+u_{18} Y_{18 j}+u_{19} Y_{19 j}\right) \\
& +u_{20} Y_{20 j}-\left(v_{10} X_{10 j}+v_{11} X_{11 j}+v_{12} X_{12 j}\right) \\
& -\left(0.066 * v_{13} X_{13 j}+0.079 * v_{14} X_{14 j}\right. \\
& \left.+0.098 * v_{15} X_{15 j}\right) \leq 0 \\
& 5.7 \times v_{13} \leq v_{14} ; \quad 3.5 \times v_{15} \leq v_{13} ; \\
& 5.7 \times v_{3} \leq v_{1} ; \quad 2.8 \times v_{2} \leq v_{3} ; \\
& 2.9 \times v_{6} \leq v_{4} ; \quad 2.5 \times v_{5} \leq v_{6} ; \\
& 5.8 \times v_{9} \leq v_{7} ; \quad 6.5 \times v_{8} \leq v_{9} \\
& 6.9 \times v_{12} \leq v_{10} ; \quad 4.5 \times v_{11} \leq v_{12} ; \\
& 5.9 \times u_{1} \leq u_{3} ; \quad 5.7 \times u_{4} \leq u_{1} ; \\
& 7.5 \times u_{2} \leq u_{4} ; \quad 6.9 \times u_{6} \leq u_{8} ; \\
& 5.6 \times u_{9} \leq u_{6} ; \quad 7.8 \times u_{7} \leq u_{9} ; \\
& 4.9 \times u_{11} \leq u_{13} ; \quad 3.9 \times u_{14} \leq u_{11} ; \\
& 5.7 \times u_{12} \leq u_{14} ; \quad 4.8 \times u_{16} \leq u_{18} ; \\
& 6.8 \times u_{19} \leq u_{16} ; \quad 5.7 \times u_{17} \leq u_{19} ; \\
& \alpha_{1}, \alpha_{2}, \alpha_{3}, \alpha_{4} \geq 0
\end{aligned}
$$$$
u_{1}, \cdots, u_{20} \geq 0.00001 ; \quad v_{1}, \cdots, v_{15} \geq 0.00001 .
$$

In the present study, 9 DMUs were investigated. The results of IFANP-NDEA and classic DEA methods are shown in Table 6. 
Table 6. Efficiency results.

\begin{tabular}{ccccccc}
\hline $\begin{array}{c}\text { Efficiency of the } \\
\text { whole system by } \\
\text { black box DEA } \\
\left(\boldsymbol{E}_{B B}\right)\end{array}$ & $\begin{array}{c}\text { Efficiency of the } \\
\text { whole system by } \\
\text { IFANP-NDEA } \\
\left(\boldsymbol{E}_{N W}\right)\end{array}$ & $\begin{array}{c}\text { Efficiency of } \\
\text { mathematics by } \\
\text { IFANP-NDEA } \\
\left(\boldsymbol{E}_{N W-M a t h}\right)\end{array}$ & $\begin{array}{c}\text { Efficiency of } \\
\text { biology by } \\
\text { IFANP-NDEA } \\
\left(\boldsymbol{E}_{N W-B i o l o g y}\right)\end{array}$ & $\begin{array}{c}\text { Efficiency of } \\
\text { chemistry by } \\
\text { IFANP-NDEA } \\
\left(\boldsymbol{E}_{N W-\text { Chemistry })}\right)\end{array}$ & $\begin{array}{c}\text { Efficiency of } \\
\text { physics by } \\
\text { IFANP-NDEA } \\
\left(\boldsymbol{E}_{N W-\text { Physics })}\right.\end{array}$ \\
\hline 1 & 1 & 0.90 & 0.99 & 0.83 & 0.92 & 0.99 \\
2 & 1 & 0.81 & 0.92 & 0.68 & 0.99 & 0.89 \\
3 & 1 & 0.87 & 0.51 & 0.99 & 0.65 & 0.80 \\
4 & 1 & 0.83 & 0.79 & 0.99 & 0.42 & 0.84 \\
5 & 1 & 0.66 & 0.75 & 0.67 & 0.55 & 0.78 \\
6 & 1 & 0.84 & 0.60 & 0.91 & 0.39 & 0.99 \\
7 & 1 & 0.91 & 0.78 & 0.93 & 0.99 & 0.99 \\
8 & 1 & 0.81 & 0.98 & 0.62 & 0.85 & 0.98 \\
9 & 1 & 0.89 & 0.83 & 0.98 & 0.42 & 0.98 \\
\hline
\end{tabular}

\section{Conclusion}

Evaluation of a system through the traditional Data Envelopment Analysis (DEA) model is similar to dealing with a black box by only focusing on the evaluation of the input and outputs and ignoring the internal operations and interactions of the processes. Therefore, the traditional DEA may identify a system as an efficient one while all of its process components are not efficient. Of note, there are cases in which all the components of a process are worse than another system while their performance is better. With these said, in order to obtain meaningful efficiency, it is better to consider the internal structure of a system whenever data is available. An approach that considers the component operations in DEA is called Network DEA (NDEA). Systems can have different structures and hence, there are different NDEA models.

The Fuzzy Analytic Network Process (IFANP) method, a combination of Intuitionistic Fuzzy Set (IFS) and Analytic Network Process (ANP) tools, is a powerful technique to obtain the relative importance of the evaluation criteria. The main objective of the present study was to investigate the efficiency of the Faculty of Basic Sciences of Islamic Azad University in two dimensions of education and research using an IFANP-NDEA method. The IFANP technique was employed to obtain the relative weights of the evaluation criteria considered in the process of modeling the problem as well as to rank the faculties based on their corresponding weights in the NDEA model.

The Faculty of Science consists of mathematics, biology, chemistry, and physics departments. Each department was investigated in the educational and research aspects. Each group had three specific inputs and three shared inputs. Specialized inputs included specialized professors and bachelor's, master's, and $\mathrm{PhD}$ students and shared inputs included general professors, staff, and area. The research outputs of each group included books, research papers, ISI articles, and research projects and educational output consisted in graduates.

The efficiency of all DMUs was equal to 1 and the DMUs did not follow any ranking. The DMUs were considered as a black box in calculating the efficiency using the traditional DEA method, that is, the internal structure was ignored. Twelve efficient universities as well as eight inefficient ones were identified.

Furthermore, the efficiency was calculated using the NDEA method by the IFANP-NDEA model $\left(E_{N W}\right)$. In this calculation, the weights of shared inputs were obtained using IFANP and then, they were used in the NDEA model. DMU5 with the efficiency value of 0.66 had the lowest efficiency and DMU7 with the efficiency of 0.91 had the highest efficiency. For DMU5, the chemistry department with the efficiency of 0.55 had the lowest efficiency and the physics department with the efficiency of 0.78 had the highest efficiency among the groups. In addition, the internal efficiency of the departments of mathematics $\left(E_{N W-\text { Math }}\right)$, biology $\left(E_{N W-\text { Biology }}\right)$, chemistry $\left(E_{N W-\text { Chemistry }}\right)$, and physics $\left(E_{N W \text {-Physics }}\right)$ was also calculated. The solution to this model was identical in both cases of considering and removing the zero unit.

The presented model allows managers to identify the points of weakness and improve overall efficiency by focusing on deficiencies. According to the results of the numerical example, the proposed model can achieve more significant results than DEA, because it considers the operations of the internal processes and prioritizes the efficient units. 


\section{References}

1. Li, Y., Chen, Y., Liang, L., et al. "DEA models for extended two-stage network structures", Omega, 40(5), pp. 611-618 (2012).

2. Färe, R. and Grosskopf, S. "Network DEA", Socioeconomic Planning Sciences, 34(1), pp. 35-49 (2000).

3. Saaty, T.L., Decision Making with Dependence and Feedback: The Analytic Network Process, RWS Publications, ISBN 0-9620317-9-8 (1996).

4. Zadeh, L.A. "Fuzzy sets, information and control", MathSciNet zbMATH, 8, pp. 338-353 (1965).

5. Zadeh, L.A. "Fuzzy sets as a basis for a theory of possibility", Fuzzy Sets and Systems, 1(1), pp. 3-28 (1978).

6. Huang, J.J. "A mathematical programming model for the fuzzy analytic network process-applications of international investment", Journal of the Operational Research Society, 63(11), pp. 1534-1544 (2012).

7. Li, G., Kou, G., Lin, C., et al. "Multi-attribute decision-making with generalized fuzzy numbers", Journal of the Operational Research Society, 66(11), pp. 1793-1803 (2015).

8. Chen, M.F., Tzeng, G.H., and Ding, C.G. "Fuzzy MCDM approach to select service provider", In The 12th IEEE International Conference on Fuzzy Systems, 1, pp. 572-577 (2003).

9. Hwang, C.L. and Yoon, K. "Multiple attribute decision making", Methods and Applications, Springer-Verlag, Berlin (1981).

10. Saaty, T.L. "A scaling method for priorities in hierarchical structures", Journal of Mathematical Psychology, 15, pp. 234-281 (1977).

11. Charnes, A., Cooper, W.W., and Rhodes, E. "Measuring the efficiency of decision-making units", European Journal of Operational Research, 2(6), pp. 429-444 (1978).

12. Ahmad, N., Berg, D., and Simons, G.R. "The integration of analytical hierarchy process and data envelopment analysis in a multi-criteria decision-making problem", International Journal of Information Technology and Decision-making, 5(02), pp. 263-276 (2006).

13. Li, H.L. and Ma, L.C. "Ranking decision alternatives by integrated DEA, AHP and Gower plot techniques", International Journal of Information Technology and Decision-making, 7(02), pp. 241-258 (2008).

14. Liu, C.C. "Simulating weight restrictions in data envelopment analysis using the subjective and objective integrated approach", Applied Economics, 38(21), pp. $2545-2552$ (2006).

15. Zhang, L. and Zhou, W.D. "Sparse ensembles using weighted combination methods based on linear programming", Pattern Recognition, 44(1), pp. 97-106 (2011).

16. Gan, W.H., Cheng, C.H., Zhong, R., et al. "Comprehensive evaluation of the efficiency of China's highway freight transport platform based on AHP-DEA", In Proceeding of the 24th International Conference on Industrial Engineering and Engineering Management 2018, pp. 346-354, Springer, Singapore (2019).

17. Li, G., Kou, G., and Peng, Y. "Dynamic fuzzy multiple criteria decision-making for performance evaluation", Technological and Economic Development of Economy, 21(5), pp. 705-719 (2015).

18. Cook, W.D., Chai, D., Doyle, J., et al. "Hierarchies and groups in DEA", Journal of Productivity Analysis, 10(2), pp. 177-198 (1998).

19. Sexton, T.R., and Lewis, H.F. "Two-stage DEA: An application to major league baseball", Journal of Productivity Analysis, 19(2-3), pp. 227-249 (2003).

20. Mikhailov, L. "Deriving priorities from fuzzy pairwise comparison judgments", Fuzzy Sets and Systems, 134(3), pp. 365-385 (2003).

21. Cook, W.D. and Green, R.H. "Evaluating power plant efficiency: a hierarchical model", Computers and $O p$ erations Research, 32(4), pp. 813-823 (2005).

22. Kao, C. "Efficiency decomposition in network data envelopment analysis: A relational model", European Journal of Operational Research, 192(3), pp. 949-962 (2009).

23. Chen, Y., Cook, W.D., Li, N., et al. "Additive efficiency decomposition in two-stage DEA", European Journal of Operational Research, 196(3), pp. 11701176 (2009).

24. Castelli, L., Pesenti, R., and Ukovich, W. "A classification of DEA models when the internal structure of the decision-making units is considered", Annals of Operations Research, 173(1), pp. 207-235 (2010).

25. Kao, C. and Hwang, S.N. "Efficiency measurement for network systems: IT impact on firm performance", Decision Support Systems, 48(3), pp. 437-446 (2010).

26. Cook, W.D., Liang, L., and Zhu, J. "Measuring performance of two-stage network structures by DEA: a review and future perspective", Omega, 38(6), pp. 423-430 (2010).

27. Chen, C. and Yan, H. "Network DEA model for supply chain performance evaluation", European Journal of Operational Research, 213(1), pp. 147-155 (2011).

28. Despotis, D.K., Koronakos, G., and Sotiros, D. "A multi-objective programming approach to network DEA with an application to the assessment of the academic research activity", Procedia Computer Science, 55, pp. 370-379 (2015).

29. Kashim, R., Kasim, M.M., and Rahman, R.A. "Measuring effectiveness of a university by a parallel network DEA model", In AIP Conference Proceedings, AIP Publishing, 1905(1), p. 040014 (2017). 
30. Guo, C., Shureshjani, R.A., Foroughi, A.A., et al. "Decomposition weights and overall efficiency in twostage additive network DEA", European Journal of Operational Research, 257(3), pp. 896-906 (2017).

31. Shafaghizadeh, S., Ebrahimnejad, S., and Navabakhsh, M. "Designing a network data envelopment analysis (ndea) model to evaluate resilience of supply chain with stochastic data", Recent Applications of Data Envelopment Analysis, Proceedings of the 15th International Conference of DEA, University of Economics, Prague, Czech Republic, ISBN: 9781854494337 (2017).

32. Mikhailov, L. and Singh, M.G. "Fuzzy analytic network process and its application to the development of decision support systems", IEEE Transactions on Systems, Man, and Cybernetics, Part C (Applications and Reviews), 33(1), pp. 33-41 (2003).

33. Mikhailov, L. and Tsvetinov, P. "Evaluation of services using a fuzzy analytic hierarchy process", Applied Soft Computing, 5(1), pp. 23-33 (2004).

34. Liu, H.W. and Wang, G.J. "Multi-criteria decisionmaking methods based on intuitionistic fuzzy sets", European Journal of Operational Research, 179(1), pp. 220-233 (2007).

35. Rouyendegh, B.D. and Erol, S. "The DEA-FUZZY ANP department ranking model applied in Iran Amirkabir University", Acta Polytechnica Hungarica, 7(4), pp. 103-114 (2010).

36. Lin, H.T. "Personnel selection using analytic network process and fuzzy data envelopment analysis approaches", Computers and Industrial Engineering, 59(4), pp. 937-944 (2010).

37. Chen, S., Chen, L., and Duan, L. "Optimization of decision-making on railway emergency plans with DEA and ANP", In ICTE 2013: Safety, Speediness, Intelligence, Low-Carbon, Innovation, pp. 1513-1519 (2013).

38. Özdemir, A. "Integrating analytic network process and data envelopment analysis for efficiency measurement of Turkish commercial banks", Banks and Bank Systems, 8(2), pp. 86-103 (2013).

39. Zhang, C. and Liu, X. "A hybrid ANP-DEA approach for vulnerability assessment in water supply system", In Proceedings of the Institute of Industrial Engineers Asian Conference 2013, pp. 1395-1403 (2013).

40. Ehsanifar, M. "DEA/AHP and its application in full ranking of decision-making units", International Journal of Quantitative Economics and Applied Management Research, ISSN: 2349-5677, 1(4) (2014).

41. Cui, M.X. and Fang, C. "A hybrid DEA-ANP method for measuring complexity in engineering projects", In 2015 IEEE International Conference on Industrial Engineering and Engineering Management (IEEM), pp. 1287-1291 (2015).
42. Kumar, A., Shankar, R., and Debnath, R.M. "Analyzing customer preference and measuring relative efficiency in telecom sector: A hybrid fuzzy AHP/DEA study", Telematics and Informatics, 32(3), pp. 447462 (2015).

43. Tavakoli, M.M., Shirouyehzad, H., and Dabestani, R. "Proposing a hybrid method based on DEA and ANP for ranking organizational units and prioritizing human capital management drivers", Journal of Modelling in Management, 11(1), pp. 213-239 (2016).

44. Abdullah, L. and Najib, L. "Sustainable energy planning decision using the intuitionistic fuzzy analytic hierarchy process: Choosing energy technology in Malaysia", International Journal of Sustainable Energy, 35(4), pp. 360-377 (2016).

45. Hu, C., Liu, F., and Hu, C. "A hybrid fuzzy DEA/AHP methodology for ranking units in a fuzzy environment", Symmetry, 9, p. 273 (2017).

46. Shariati, S., Abedi, M., Saedi, A., Yazdani-Chamzini, A., Tamošaitienè, J., Šaparauskas, J., and Stupak, S. "Critical factors of the application of nanotechnology in construction industry by using ANP technique under fuzzy intuitionistic environment", Journal of Civil Engineering and Management, 23(7), pp. 914925 (2017).

47. Salehian, F., Razmi, J., and Jolai, F. "A hybrid ranking approach based on fuzzy analytical hierarchy process and data envelopment analysis: Road maintenance and transport organization of Iran", Journal of Intelligent and Fuzzy Systems, 34(4), pp. 2373-2383 (2018).

48. Mazumder, S., Kabir, G., Hasin, M., et al. "Productivity benchmarking using Analytic Network Process (ANP) and Data Envelopment Analysis (DEA)", Big Data and Cognitive Computing, 2(3), p. 27 (2018).

49. Li, Z., Sun, D., and Zeng, S. "Intuitionistic fuzzy multiple attribute decision-making model based on weighted induced distance measure and its application to investment selection", Symmetry, 10(7), p. 261 (2018).

50. Kao, C. "Efficiency measurement for hierarchical network systems", Omega, 51, pp. 121-127 (2015).

51. Kao, C. "Network data envelopment analysis: A review", European Journal of Operational Research, 239(1), pp. 1-16 (2014).

52. Lee, B.L. and Worthington, A.C. "A network DEA quantity and quality-orientated production model: An application to Australian university research services", Omega, 60, pp. 26-33 (2016).

53. Koronakos, G., Chytilova, L., and Sotiros, D. "Measuring the research performance of UK computer science departments via network DEA", In 2019 10th International Conference on Information, Intelligence, Systems and Applications (IISA), IEEE, pp. 1-7 (2019). 
54. Koronakos, G. "A taxonomy and review of the network data envelopment analysis literature", In Machine Learning Paradigms, Springer, Cham, pp. 255-311 (2019).

55. Chen, Y., Cook, W.D., Kao, C., et al. "Network DEA pitfalls: Divisional efficiency and frontier projection", In Data Envelopment Analysis, Springer, Boston, MA. pp. 31-54 (2014).

56. Atanassov, K.T. "Intuitionistic fuzzy sets", Fuzzy Sets and Systems, 20(1), pp. 87-96 (1986).

57. Atanassov, K.T. "Intuitionistic fuzzy sets", In Intuitionistic Fuzzy Sets, Physica, Heidelberg, pp. 1-137 (1999).

58. Mikhailov, L., and Singh, M.G. "Fuzzy assessment of priorities with application to competitive bidding", Journal of Decision Systems, 8(1), pp. 11-28 (1999).

\section{Appendix}

Consider Model (10) again. We use the $L_{\infty}$-norm in formula (A.1):

$$
\mu_{\tilde{P}}(w)=\min _{k}\left\{\begin{array}{lc}
\left\|1-\frac{R_{k} w}{d_{k}}\right\|_{\infty} ; & 0 \leq R_{k} w \leq d_{k}, \\
1 ; & R_{k} w \leq 0, \\
0 ; & R_{k} w \geq d_{k}, \\
\left.\mid w_{1}+\cdots+w_{n}=1\right]
\end{array}\right\}
$$

Then, we will have:

$$
\begin{aligned}
& \mu_{\tilde{P}}\left(w_{\max }^{*}\right) \\
& =\max _{k} \min \left\{\begin{array}{ll}
\left\|1-\frac{R_{k} w}{d_{k}}\right\|_{\infty} ; & 0 \leq R_{k} w \leq d_{k}, \\
1 ; & R_{k} w \leq 0, \\
0 ; & R_{k} w \geq d_{k}, \\
\left.\mid w_{1}+\cdots+w_{n}=1\right]
\end{array}\right\}
\end{aligned}
$$

Finally, Model (A.3) is formulated, which is the same as Model (14). Therefore, we convert the multiobjective function into a single-objective one by using the $L_{\infty}$-norm.

$\max \alpha$,

$$
\begin{array}{ll}
\text { s.t. } & \alpha \leq 1-\frac{R_{k} w}{d_{k}}, \quad k=1, \cdots, m, \\
& \sum_{i=1}^{n} w_{i}=1, \quad w_{i}>0, \quad 0 \leq \alpha \leq 1,
\end{array}
$$

$$
\alpha=\max _{k} \min \left\{\begin{array}{ll}
\left\|1-\frac{R_{k} w}{d_{k}}\right\|_{\infty} ; & 0 \leq R_{k} w \leq d_{k}, \\
1 ; & R_{k} w \leq 0, \\
0 ; & R_{k} w \geq d_{k}, \\
\left.\mid w_{1}+\cdots+w_{n}=1\right]
\end{array}\right\}
$$

\section{Biographies}

Elahe Shariatmadari Serkani is currently a $\mathrm{PhD}$ candidate of Industrial Engineering at the Science and Research Branch of Islamic Azad University of Tehran. Her specific areas of expertise include data envelopment analysis, operations research, and decision making.

Farhad Hosseinzadeh Lotfi is currently a Full Professor in Mathematics at the Science and Research Branch, Islamic Azad University (IAU), Tehran, Iran. In 1992, he received his BSc degree in Mathematics from Yazd University, Yazd, Iran. He also received his MSc in Operations Research from the IAU, Lahijan, Iran, in 1996 and PhD in Applied Mathematics (OR) from the IAU, Science and Research Branch, Tehran, Iran in 2000. He is Editor-in-Chief and a member of editorial board of the Journal of Data Envelopment Analysis and Decision Science. He is also Directorin-Charge and a member of the editorial board of the International Journal of Industrial Mathematics. His research interests are mathematics, operations research, data envelopment analysis, and efficiency.

Esmaeil Najafi is an Associate Professor of Industrial Engineering at the Science and Research Branch of Islamic Azad University of Tehran. His research interests are industrial engineering, applied and computational mathematics, operations management, and optimization.

Mahnaz Ahadzadeh Namin received his $\mathrm{PhD}$ in Applied Mathematics from the Science and Research Branch, Islamic Azad University, Tehran, Iran, in 2009. She is currently an Assistant Professor at the Shahr-e-Qods Branch of Islamic Azad University. Her research interests are data envelopment analysis, efficiency analysis, applied mathematics, productivity analysis, and applied econometrics. 